\title{
OCORRÊNCIAS DE MAMÍFEROS AQUÁTICOS NO ESTADO DE PERNAMBUCO, BRASIL
}

\author{
Occurrences of aquatic mammals in the \\ State of Pernambuco, Brazil
}

\author{
Fernanda Loffler Niemeyer Attademo ${ }^{1,2,3^{*}}$, João Luiz Xavier do Nascimento ${ }^{4}$, \\ Gláucia Pereira de Sousa ${ }^{3}$, João Carlos Gomes Borges ${ }^{5,6}$, \\ Jociery Einhardtt Vergara-Parentee, Ana Emília Barboza de Alencar ${ }^{7,8}$, \\ Ernesto Frederico Foppe ${ }^{9}$, Augusto Carlos da Boaviagem Freire ${ }^{2}$, \\ Radan Elvis Matias de Oliveira ${ }^{1,2}$, Régis Pinto de Lima ${ }^{10}$, Fábia de Oliveira Luna ${ }^{3}$ \\ ${ }^{1}$ Centro de Estudos e Monitoramento Ambiental. E-mail: niemeyerattademo@yahoo.com.br* \\ 2 Projeto Cetáceos da Costa Branca, Laboratório de Monitoramento de Biota Marinha Universidade do \\ Estado do Rio Grande do Norte (PCCB/UERN) \\ ${ }^{3}$ Instituto Chico Mendes de Conservação da Biodiversidade/Centro Nacional de \\ Pesquisa e Conservação de Mamíferos Aquáticos \\ ${ }^{4}$ Instituto Chico Mendes de Conservação da Biodiversidade/Centro Nacional de \\ Pesquisa e Conservação de Biodiversidade Marinha do Nordeste \\ ${ }^{5}$ Projeto Viva o Peixe-Boi-Marinho, Programa Nacional para a Conservação dos \\ Peixes-Bois-Marinhos, Fundação Mamíferos Aquáticos \\ ${ }^{6}$ Programa de Pós-Graduação em Ecologia e Monitoramento Ambiental, Universidade Federal da Paraíba \\ ${ }^{7}$ GISdrone Consultoria \& Mapeamento Aéreo \\ ${ }^{8}$ Programa de Pós-Graduação em Geociências (PPGEOC), Departamento de Geologia, \\ Universidade Federal de Pernambuco \\ ${ }^{9}$ Programa de Pós-Graduação em Desenvolvimento e Meio Ambiente (Prodema), \\ Universidade Federal de Sergipe \\ ${ }^{10}$ Instituto Chico Mendes de Conservação da Biodiversidade/Estação Ecológica de Tamoios
}

\section{RESUMO}

Os mamíferos aquáticos utilizam como habitat todo o território brasileiro; entretanto, até o presente momento não se tinha uma descrição sistematizada das espécies que ocorrem no litoral do estado de Pernambuco. $\mathrm{O}$ atendimento aos encalhes é uma importante ferramenta para obtenção desses registros, assim como para gerar informações sobre as populações e respectivas ameaças às quais estão sujeitas. Este trabalho teve como objetivo descrever a ocorrência, diversidade e distribuição de mamíferos aquáticos no estado de Pernambuco, Brasil. O conhecimento adquirido foi oriundo do banco de dados das instituições da Rede de Encalhes de Mamíferos Aquáticos do Nordeste, que atuaram no estado entre 1984 e 2015, contemplando animais vivos e mortos. Foram registrados 157 eventos de encalhes em Pernambuco, correspondendo a 18 espécies de mamíferos aquáticos. Sotalia

Recebido em: 23/01/2020

Aprovado em: 25/05/2020

Publicado em: 30/08/2020 
guianensis foi a espécie mais abundante (28,7\%), seguida por Tursiops truncatus (17,2\%) e Trichechus manatus (9,6\%). Foi identificada a presença de espécies ameaçadas e migratórias, sendo as atividades antrópicas a maior ameaça. Os municípios de Recife e Olinda apresentavam-se como área de descontinuidade de ocorrência do peixe-boi- marinho; entretanto, este estudo identificou animais nativos nessas localidades. $\mathrm{O}$ atendimento sistematizado aos encalhes e as campanhas educativas são essenciais para garantir a conservação dessas espécies no estado.

Palavras-chave: encalhe, conservação, rede de encalhe.

\begin{abstract}
Aquatic mammals occur throughout the Brazil territory. However, until now there are no descriptions of the species that occur in the coast of Pernambuco State. Stranding assistance is an important tool for the record of aquatic mammal species and for obtaining information about populations and their respective threats. This study aimed to describe the occurrence, diversity and distribution of aquatic mammals in Pernambuco State, Brazil. The knowledge acquired came from the database from institutions within the Northeast Marine Mammals Stranding Network (REMANE) that acted in the state between 1984 and 2015, contemplating live and dead animals. A number of 157 stranding events were recorded in Pernambuco State, corresponding to 18 aquatic mammal species. Sotalia guianensis was the most abundant species $(28,7 \%)$, followed by Tursiops truncatus $(17,2 \%)$ and Trichechus manatus $(9,6 \%)$. The presence of threatened and migratory species was identified, being the anthropic activities the biggest threat. Recife counties and the Olinda County presented itself as discontinued area of the marine manatee; however, this study showed the occurrence of native animals in these localities. Systematized assistance to stranding and educational campaigns are essentials to guarantee the conservations of these species in Pernambuco.
\end{abstract}

Keyword: stranding, conservation, network of strandings.

\title{
INTRODUÇÃO
}

Os mamíferos aquáticos ocorrem em todo o território brasileiro, contemplando as ordens Cetartiodactyla, Sirenia e Carnivora (Cubas; Silva \& Catão-Dias, 2014; ICMBio, 2018). Na região Nordeste do país, apesar do grande avanço dos estudos provenientes das instituições da Rede de Encalhes de Mamíferos Aquáticos do Brasil (Remab), em especial a sub-rede da região Nordeste (Rede de Encalhes de Mamíferos Aquáticos do Nordeste - Remane), os dados referentes a essas espécies ainda são escassos em algumas unidades da Federação.

Por meio dos encalhes de mamíferos aquáticos tem sido possível gerar informações sobre a ocorrência, distribuição e abundância relativa (Berrow, 2001; Parente et al., 2017; Borges et al., 2019), conforme pode ser constatado nos estudos sobre diversidade de cetáceos na Bacia de Campos (Parente et al., 2017) e de mamíferos marinhos na Bacia de SergipeAlagoas (Borges et al., 2019). Além disso, permite inferir contribuições sobre status populacio- 
nais, morfologia, doenças e história natural, sobretudo quando se trata de séries amostrais de longo prazo (Geraci \& St. Aubin, 1979; Parente et al., 2017). Esses eventos podem ser decorrentes de diversos fatores, tais como: capturas acidentais (Dans et al., 2003), atropelamentos por embarcações motorizadas (Borges et al., 2007), ingestão de resíduos sólidos (Attademo et al., 2015), agentes patogênicos (Ruoppolo et al., 2010; Fire et al., 2015), entre outros.

Os registros de encalhes (Meirelles et al., 2016; Costa et al., 2017), acrescidos daqueles realizados por meio de avistagens (Parente; Lima \& Vergana-Parente, 2006; Alves et al., 2013), permitiram relacionar as espécies ora apresentadas, constituindo um importante caminho para ampliar o conhecimento sobre a ocorrência desses grupos taxonômicos.

No Brasil, a partir das evidências reportadas, constata-se uma riqueza de biodiversidade marinha, contemplando espécies migratórias como a baleia jubarte (Megaptera novaeangliae) e cachalote (Physeter macrocephalus), as quais estão, respectivamente, quase ameaçadas de extinção e em estado vulnerável, todas sofrendo diferentes ameaças que precisam ser mais bem conhecidas para que os impactos nas populações possam ser minimizados (ICMBio, 2018). Na região Nordeste, os registros a partir de encalhes e observações têm possibilitado a ampliação do conhecimento da mastofauna aquática (Parente et al., 2004; Meirelles et al., 2016), inclusive para Pernambuco, haja vista que as ferramentas e os métodos de análises para obtenção dessas informações são ainda reduzidos (Araújo et al., 2008; Alves et al., 2013).

Este trabalho teve por objetivo reportar a ocorrência e diversidade de mamíferos aquáticos no estado de Pernambuco, contribuindo para ampliar o conhecimento sobre a biodiversidade marinha, bem como propor ações que possam auxiliar nas estratégias de conservação das diferentes espécies envolvidas.

\section{MATERIAL E MÉTODOS}

\section{Área de estudo}

O litoral do estado de Pernambuco, Brasil, possui 13 municípios que se dividem na porção norte, localizada entre as praias de Carne de Vaca ( $07^{\circ} 32^{\prime} 36,07^{\prime \prime}$ S $034^{\circ} 50^{\prime} 31,9^{\prime \prime} \mathrm{O}$ ) e Barra de Jangada ( $\left.08^{\circ} 13^{\prime} 15,15^{\prime \prime} \mathrm{S} 034^{\circ} 55^{\prime} 29,70^{\prime \prime} \mathrm{O}\right)$, e sul, estendendo-se da Ilha do Amor $\left(08^{\circ} 13^{\prime} 28,62^{\prime \prime} \mathrm{S} 034^{\circ} 55^{\prime} 31,48^{\prime \prime} \mathrm{O}\right)$ até a praia de São José da Coroa Grande (08 $54^{\prime} 49,61^{\prime \prime}$ $S 35^{\circ} 09^{\prime}$ 09,59" O). Faz parte também do estado de Pernambuco o arquipélago de Fernando de Noronha, distante $545 \mathrm{~km}$ da capital pernambucana.

Para a determinação do tamanho do litoral de cada município foi utilizado o Software QGIS 64 Bit, licenciado sob a General Public License (GNU), versão 2.18.10. No caso das ilhas de Itamaracá e Fernando de Noronha, foi considerada toda a extensão do litoral de ambas, devido à área susceptível aos encalhes.

A sede do Instituto Chico Mendes de Conservação da Biodiversidade/Centro Nacional de Pesquisa e Conservação de Mamíferos Aquáticos (ICMBio/CMA) localizava-se na Ilha de Itamaracá, litoral norte do estado, sendo este o local de destinação dos animais. No litoral sul, entre os municípios de Tamandaré e São José da Coroa Grande, divisa com o estado de Alagoas, está inserida a Área de Proteção Ambiental Costa dos Corais (Apacc), administrada pelo Governo Federal por meio do ICMBio (Brasil, 1997).

\section{Animais}

No período de março de 1984 a dezembro de 2015, as ocorrências de encalhes foram reportadas por colaboradores (pescadores, marisqueiras, banhistas e moradores locais), 
identificados a partir de campanhas educativas realizadas pelo Centro Nacional de Pesquisa e Conservação de Mamíferos Aquáticos, pelo Instituto Chico Mendes de Conservação da Biodiversidade (ICMBio/CMA), pela Fundação Mamíferos Aquáticos (FMA) e pelo Instituto Mamíferos Aquáticos (IMA), todos pertencentes à Remane. Após o recebimento das notificações, uma equipe técnica de resgate foi mobilizada até o local da ocorrência, sendo procedidos o registro e resgate dos animais e carcaças, quando vivos ou mortos, respectivamente.

Os procedimentos seguiram o disposto no Protocolo de Conduta para Encalhes de Mamíferos Aquáticos (Ibama, 2005). Para os animais vivos, após avaliação clínica por médico veterinário, onde foram verificados os sinais vitais estáveis, estado de alerta, boa condição corporal e ausência de debilidades aparentes (Ibama, 2005), sempre que possível foi realizada a tentativa de reintrodução imediata. Nas ocasiões em que não houve essa possibilidade, os espécimes foram transferidos para a Unidade de Reabilitação do ICMBio/ CMA, na Ilha de Itamaracá, em Pernambuco.

Os animais foram agrupados de acordo com os grupos taxonômicos: Sirênios, Cetáceos, Pinípedes e Mustelídeos. A identificação taxonômica ocorreu de acordo com os guias de identificação de mamíferos aquáticos (Jefferson; Leatherwood \& Webber, 1993; Reeves et al., 2002; Lodi \& Borobia, 2013). Todas as informações obtidas foram inseridas em planilhas eletrônicas, previamente padronizadas pela instituição, contendo as seguintes informações: número do registro (sequencial), espécie, sexo (macho, fêmea ou indeterminado), data (dia, mês, ano), faixa etária (filhote, juvenil, adulto, indeterminado), situação de encalhe (vivo ou morto), localidade e coordenadas geográficas.

Para a classificação das espécies quanto ao estado de conservação, foi utilizada a Lista Nacional Oficial de Espécies da Fauna Brasileira Ameaçada de Extinção (ICMBio, 2018). A relação de espécies contidas nos apêndices da Convenção sobre a Conservação das Espécies Migratórias de Animais Silvestres (CMS) foi obtida da Portaria MMA n⿳ 12, de 23 de janeiro de 2018; enquanto a lista de espécies contidas nos apêndices da Convenção sobre o Comércio Internacional das Espécies da Flora e Fauna Selvagens Ameaçadas de Extinção (Cites) foi obtida no site da convenção (Cites, 2017).

Os animais encontrados mortos, a depender do tamanho e peso da carcaça, foram transferidos para o Laboratório de Necropsia do referido centro, sendo realizado, quando possível, o exame necroscópico e colheita de amostras biológicas para pesquisas complementares. Todas as amostras foram encaminhadas para o acervo de material biológico do ICMBio/ CMA. Para os animais de maior porte, ou quando o resgate era inviável (devido à acessibilidade), o procedimento de necropsia e destinação da carcaça foi realizado no local de encalhe.

Tendo em vista o avançado estado de decomposição da maioria das carcaças, em alguns casos não foi possível identificar a causa da morte. Nas condições em que o estado de conservação da carcaça tornou essa avaliação possível, para efeitos deste estudo as causas de encalhe e de morte foram categorizadas como: natural (desencadeadas por enfermidades, predação por tubarões), antrópica (emalhe em redes de pesca, caça, arpão, faca) e indeterminada (quando a identificação foi impossibilitada).

A identificação dos anos em que ocorreram os fenômenos meteorológicos de El Niño ou La Niña foi obtida no site do Instituto Nacional de Pesquisas Espaciais (Inpe, 2018).

\section{Análises estatísticas}

Todos os dados foram digitados em planilha eletrônica (Microsoft Office Excel 2010, Microsoft Corporation, Redmond, WA, EUA), sendo expressos por cálculo percentual sim- 
ples. O valor médio do número de encalhes por ano e por meses foi analisado pelo teste de Kruskal-Wallis. Foi obtida a relação entre o número de espécies ameaçadas e não ameaçadas, encalhadas na região, através do teste de Mann-Whitney. Para relacionar o número de registros de encalhes entre a influência de fenômenos (El Niño e La Niña), foram utilizados dois testes, sendo o primeiro o Qui-quadrado, para verificar a influência de algum fenômeno, e, em seguida, o teste de Mann-Whitney, utilizado para verificar a diferença entre os dois tipos de fenômeno. Para a relação entre o número de encalhes e a extensão do município, foi utilizada a correlação de Spearman e, para verificar a existência de diferença estatística significante entre o número de encalhes por município, foi realizado o teste Quiquadrado, considerando um valor de $\mathrm{p}<0,05$ estatisticamente significativo. Para as análises, foi utilizado o programa The R Project for Statistical Computing (8/2018).

\section{RESULTADOS}

Foram registrados 157 eventos de encalhes no estado de Pernambuco, compreendendo 18 espécies de mamíferos aquáticos, conforme apresentado na Tabela I.

\begin{tabular}{|c|c|c|c|c|c|c|}
\hline Classificação & Nome popular & Ameaça & Cites & CMS & Hábito & n (\%) \\
\hline \multicolumn{7}{|l|}{ Ordem CARNIVORA } \\
\hline $\begin{array}{l}\text { Arctocephalus australis (Zimmermann, } \\
\text { 1783) }\end{array}$ & Lobo-marinho-do-sul & NA & II & II & $\cos$ & $1(0,6)$ \\
\hline Arctocephalus tropicalis (Gray, 1872) & Lobo-marinho-subantártico & NA & II & $\ldots$ & $\cos$ & $1(0,6)$ \\
\hline \multicolumn{7}{|l|}{ Família Mustelidae } \\
\hline Lontra longicaudis (Olfers, 1818) & Lontra do rio & NT & I & $\ldots$ & EST & $6(3,8)$ \\
\hline \multicolumn{7}{|l|}{ Ordem CETARTIODACTYLA } \\
\hline \multicolumn{7}{|l|}{ Infraordem CETACEA } \\
\hline \multicolumn{7}{|l|}{ Subordem MYSTICETI } \\
\hline \multicolumn{7}{|l|}{ Família Balaenopteridae } \\
\hline Megaptera novaeangliae (Borowski, 1781) & Baleia jubarte & NT & I & I & OCE & $7(4,5)$ \\
\hline \multicolumn{7}{|l|}{ Subordem ODONTOCETI } \\
\hline Physeter macrocephalus (Linnaeus, 1758) & Cachalote & VU & I & I e II & OCE & $9(5,7)$ \\
\hline \multicolumn{7}{|l|}{ Família Kogiidae } \\
\hline Kogia sima (Owen, 1866) & Cachalote-anão & $\mathrm{LC}$ & II & $\ldots$ & OCE & $5(3,2)$ \\
\hline \multicolumn{7}{|l|}{ Família Ziphiidae } \\
\hline Ziphius cavirostris (Cuvier, 1823) & Baleia-bicuda-de-cuvier & DD & II & $\ldots$ & OCE & $3(1,9)$ \\
\hline \multicolumn{7}{|l|}{ Família Delphinidae } \\
\hline Globicephala macrorhynchus (Gray, 1846) & Baleia-piloto-de-aleta-curta & $\mathrm{LC}$ & II & $\ldots$ & OCE & $5(3,2)$ \\
\hline Globicephala sp. & $\ldots$ & $\ldots$ & $\ldots$ & $\ldots$ & $\ldots$ & $1(0,6)$ \\
\hline Pseudorca crassidens (Owen, 1846) & Falsa-orca & $\mathrm{LC}$ & II & $\ldots$ & $\begin{array}{l}\text { OCE, } \\
\text { COS }\end{array}$ & $1(0,6)$ \\
\hline Peponocephala electra (Gray, 1846) & Golfinho-cabeça-de-melão & LC & $\ldots$ & $\ldots$ & OCE & $5(3,2)$ \\
\hline Sotalia guianensis (Van Bénedén, 1864) & Boto-cinza & VU & I & II & $\cos$ & $\begin{array}{c}45 \\
(28,7)\end{array}$ \\
\hline Stenella clymene (Gray, 1850) & Golfinho-clímene & $\mathrm{LC}$ & II & $\cdots$ & $\begin{array}{l}\text { OCE, } \\
\text { COS }\end{array}$ & $7(4,5)$ \\
\hline Stenella frontalis (Cuvier, 1829) & Golfinho-pintado-do-atlântico & DD & II & $\ldots$ & $\begin{array}{l}\text { OCE, } \\
\text { COS }\end{array}$ & $1(0,6)$ \\
\hline Stenella longirostris (Gray, 1828) & Golfinho-rotador & DD & II & $\cdots$ & $\begin{array}{l}\text { OCE, } \\
\text { COS }\end{array}$ & $7(4,5)$ \\
\hline Stenella sp. & $\ldots$ & .. & .. & .. &.. & $1(0,6)$ \\
\hline
\end{tabular}


(continuação Tabela I)

\begin{tabular}{|c|c|c|c|c|c|c|}
\hline Classificação & Nome popular & Ameaça & Cites & CMS & Hábito & n (\%) \\
\hline $\begin{array}{l}\text { Steno bredanensis (G. Cuvier in Lesson, } \\
1828 \text { ) }\end{array}$ & Golfinho-de-dentes-rugosos & $\mathrm{LC}$ & II & ... & $\begin{array}{l}\text { OCE, } \\
\text { COS }\end{array}$ & $5(3,2)$ \\
\hline Tursiops truncatus (Montagu, 1821) & Golfinho-nariz-de-garrafa & $\mathrm{DD}$ & II & I & $\begin{array}{l}\text { OCE, } \\
\text { COS }\end{array}$ & $\begin{array}{c}27 \\
(17,2)\end{array}$ \\
\hline Cetáceo indeterminado & Indeterminado & .. & .. & .. & .. & $5(3,2)$ \\
\hline \multicolumn{7}{|l|}{$\begin{array}{l}\text { Ordem SIRENIA } \\
\text { Família Trichechidae }\end{array}$} \\
\hline Trichechus manatus (Linnaeus, 1758) & Peixe-boi-marinho & EN & I & I e II & $\cos$ & $15(9,6)$ \\
\hline
\end{tabular}

Legenda: Cites (Convenção sobre o Comércio Internacional das Espécies da Flora e Fauna Selvagens Ameaçadas de Extinção); CMS (Convenção sobre a Conservação das Espécies Migratórias de Animais Silvestres). Legenda para grau de ameaça: LC (menos preocupante); DD (dados insuficientes); NA (não aplicável); NT (quase ameaçado); VU (vulnerável); EN (em perigo). Legenda para hábito: COS (costeiro); OCE (oceânico); EST (estuarino).

Entre os registros de encalhes, os botos-cinza, S. guianensis, com 28,7\% (45/157), foram os mais abundantes, seguidos pelos golfinhos-nariz-de-garrafa, T. truncatus, com 17,2\% (27/157); peixes-bois-marinhos, T. manatus, com 9,6\% (15/157); e cachalotes, P. macrocephalus, com 5,7\% (9/157).

Em meio as espécies identificadas, algumas encontram-se listadas no Livro Vermelho da Fauna Brasileira Ameaçada de Extinção (ICMBio, 2018), sendo o peixe-boi-marinho (T. manatus) a espécie mais ameaçada da região, classificada como “em perigo" (EN). De acordo com os dados analisados, existe diferença entre a média e a variabilidade das variáveis envolvidas entre as espécies ameaçadas e não ameaçadas. Além disso, o teste de Mann-Whitney comprovou essa diferença, onde foi verificado que ( $p$ - valor $=0,01835$ ) é menor que o nível de significância $(\alpha=0,05)$, ou seja, há evidência estatística de que existe diferença entre as espécies ameaçadas e não ameaçadas (Figura 1).

Conforme descrito na Tabela I, cinco espécies em Pernambuco estão listadas no Apêndice I da Cites e onze no Apêndice II. No tocante à CMS, da qual o Brasil é signatário, duas espécies estão listadas no Apêndice I; duas espécies no Apêndice II; e duas espécies nos Apêndices I e II.

Quanto à situação de encalhe, $20,4 \% \quad(32 / 157)$ estavam vivos e $79,6 \%(125 / 157)$, mortos. Com relação às causas de mortalidade dos animais, 28,0\% (35/125) foram de natureza antrópica; $12,0 \%(15 / 125)$ por causas naturais; e $60 \%(75 / 125)$ indeterminada, devido ao avançado estado de decomposição em que as carcaças se encontravam.

Em função do alto grau de decomposição de muitas carcaças registradas, não foi possível a iden-

Figura 1 - Correlação entre espécies ameaçadas e não ameaçadas, utilizando o teste de Mann-Whitney

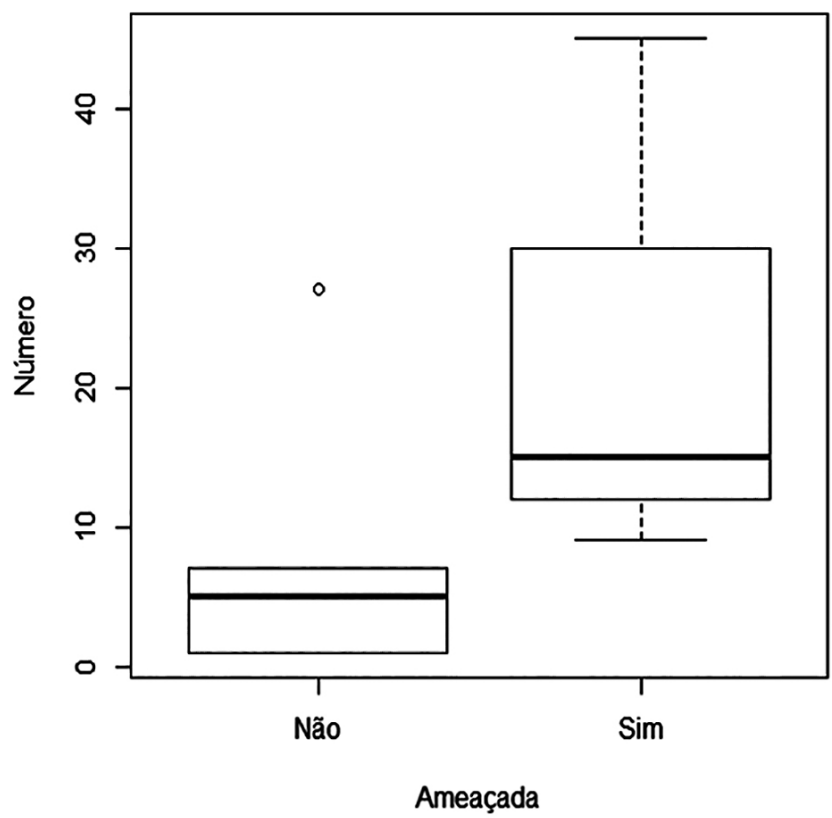


tificação do sexo em todos os animais. Dessa forma, a proporção foi de $24 \%$ de fêmeas, $41 \%$ de machos e $35 \%$ de sexo não identificado. A Tabela II apresenta essa proporção por cada espécie resgatada em Pernambuco.

Os animais vivos, as carcaças e as amostras provenientes deste estudo encontram-se tombados e sob a égide do Instituto Chico Mendes de Conservação da Biodiversidade (ICMBio).

\begin{tabular}{|c|c|c|c|}
\hline Espécie & Fêmeas & Machos & Indeterminados \\
\hline Arctocephalus australis & 0 & $1(100 \%)$ & 0 \\
\hline Arctocepahalus tropicalis & $1(100 \%)$ & 0 & 0 \\
\hline Lontra longicaudis & $2(33,0 \%)$ & $3(50,0 \%)$ & $1(16,6 \%)$ \\
\hline Megaptera novaeangliae & 0 & $2(28,6 \%)$ & $5(71,4 \%)$ \\
\hline Physeter macrocephalus & $1(11,1 \%)$ & $4(44,4 \%)$ & $4(44,4 \%)$ \\
\hline Kogia sima & $3(60,0 \%)$ & $2(40,0 \%)$ & 0 \\
\hline Ziphius cavirostris & $3(100 \%)$ & 0 & 0 \\
\hline Globicephala macrorhynchus & 0 & $2(40,0 \%)$ & $3(60,0 \%)$ \\
\hline Globicephala sp. & 0 & 0 & $1(100 \%)$ \\
\hline Pseudorca crassidens & 0 & $1(100 \%)$ & 0 \\
\hline Peponocephala electra & $2(40,0 \%)$ & $3(60,0 \%)$ & 0 \\
\hline Sotalia guianensis & $8(17,8 \%)$ & $25(55,5 \%)$ & $12(26,7 \%)$ \\
\hline Stenella clymene & $4(57 \%)$ & $2(29 \%)$ & $1(14 \%)$ \\
\hline Stenella frontalis & 0 & $1(100 \%)$ & 0 \\
\hline Stenella longirostris & $2(28,6 \%)$ & $3(42,9 \%)$ & $2(28,6 \%)$ \\
\hline Stenella sp. & 0 & $1(100 \%)$ & 0 \\
\hline Steno bredanensis & $2(40,0 \%)$ & $3(60,0 \%)$ & 0 \\
\hline Tursiops truncatus & $3(11,1 \%)$ & $7(25,9 \%)$ & $17(63,0 \%)$ \\
\hline Trichechus manatus & $7(46,7 \%)$ & $3(20,0 \%)$ & $5(33,3 \%)$ \\
\hline Cetáceo indeterminado & 0 & $1(20,0 \%)$ & $4(80,0 \%)$ \\
\hline Geral & $38(24,2 \%)$ & $64(44,8 \%)$ & $55(35,0 \%)$ \\
\hline
\end{tabular}

Em todas as regiões de Pernambuco, incluindo a ilha de Fernando de Noronha, foi registrada a presença de mamíferos aquáticos (Figura 2). A mesma figura mostra a gradação hipsométrica (análise de Kernel), onde as áreas mais escuras correspondem àquelas com a maior concentração de encalhes.

Os municípios com os maiores números de encalhes foram: Recife (28 registros), Ipojuca (24 registros) e Ilha de Itamaracá (23 registros) (Tabela III). Com relação à região do encalhe, o litoral norte apresentou 66,2\% (104/157) dos registros; seguido pelo litoral sul, com 28,7\% (45/157); e pela ilha oceânica de Fernando de Noronha, com 3,2\% (5/157) do total.

Conforme observado no teste estatístico, existe diferença das frequências de encalhes entre os municípios, onde foi verificado que ( $\mathrm{p}$ - valor $=2.2 \mathrm{e}-16)$ é menor que o nível de significância $(\alpha=0,05)$, ou seja, existe diferença estatisticamente significativa entre o número de encalhes por município. 
Figura 2 - Distribuição espacial dos encalhes no litoral de Pernambuco (análise de Kernel) e na ilha de Fernando de Noronha

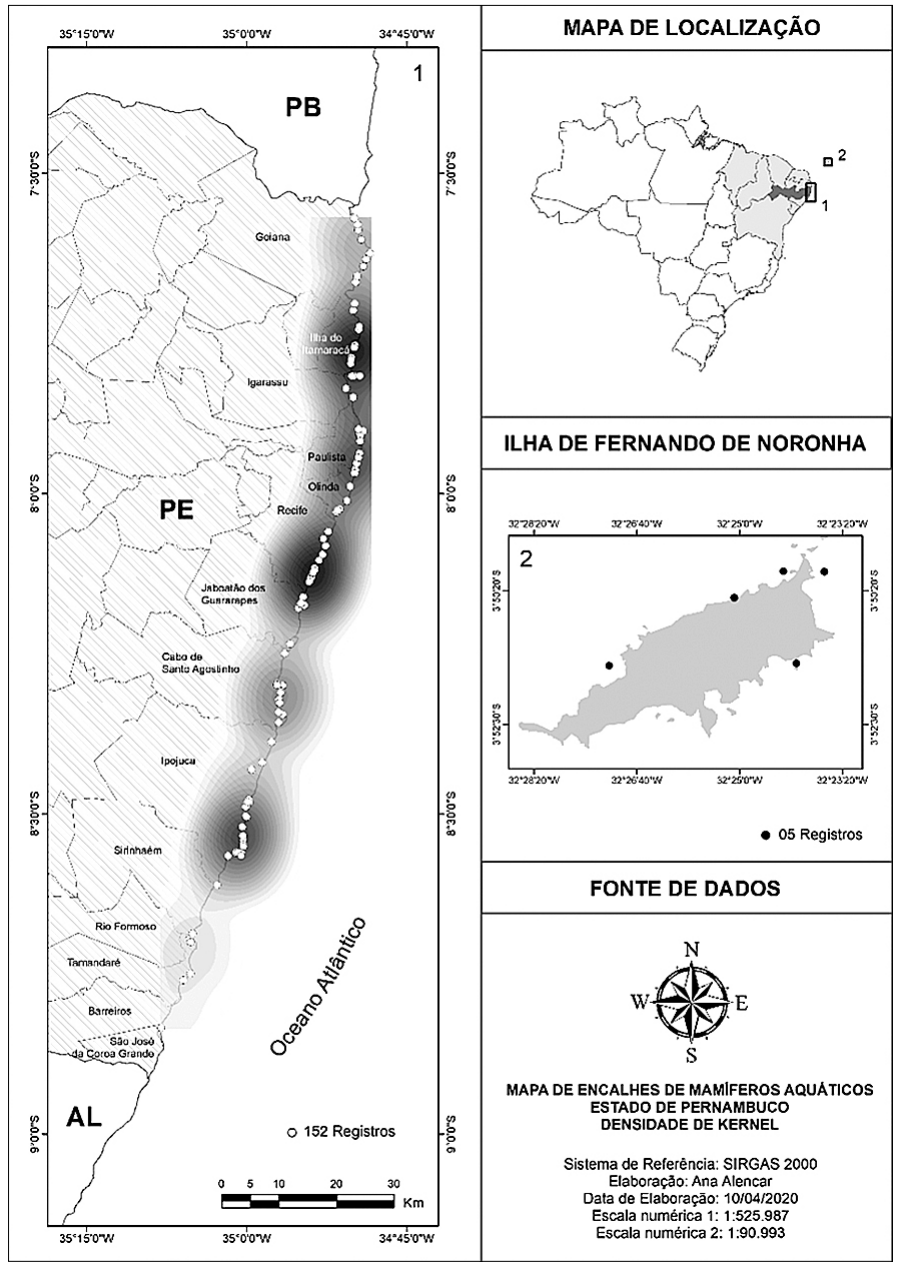

Tabela III - Número de registros de encalhe de mamíferos aquáticos, por município, no estado de Pernambuco

\begin{tabular}{ccccc}
\hline Município & Extensão (km) & Litoral & $\mathbf{N}^{\circ}$ de encalhes (N/\%) & $\begin{array}{c}\mathbf{N}^{\circ} \text { de encalhes } \\
\text { por km }\end{array}$ \\
\hline Goiana & 20,35 & Norte & $11(7,0 \%)$ & 0,54 \\
Ilha de Itamaracá & 36,79 & Norte & $23(14,6 \%)$ & 0,63 \\
Igarassu & 3,51 & Norte & $7(4,5 \%)$ & 1,99 \\
Olinda & 10,89 & Norte & $17(10,8 \%)$ & 1,56 \\
\hline Município & Extensão (km) & Litoral & $\mathbf{N}^{\circ}$ de encalhes (N/\%) & $\begin{array}{c}\mathbf{N}^{\circ} \text { de encalhes } \\
\text { por km }\end{array}$ \\
\hline Paulista & 14,01 & Norte & $13(8,3 \%)$ & 0,93 \\
Recife & 13,43 & Norte & $28(17,8 \%)$ & 2,08 \\
Jaboatão dos Guararapes & 8,34 & Norte & $5(3,2 \%)$ & 0,60 \\
Cabo de Santo Agostinho & 21,04 & Sul & $11(7,0 \%)$ & 0,52 \\
Ipojuca & 31,88 & Sul & $24(15,3 \%)$ & 0,75 \\
Sirinhaém & 10,87 & Sul & $3(1,9 \%)$ & 0,28 \\
Rio Formoso & 10,79 & Sul & $0(0,0 \%)$ & 0,00 \\
Tamandaré & 12,20 & Sul & $5(3,2 \%)$ & 0,41 \\
Barreiros & 10,14 & Sul & $0(0,0 \%)$ & 0,00 \\
São José da Coroa Grande & 6,45 & Sul & $2(1,3 \%)$ & 0,31 \\
Fernando de Noronha & 37,32 & $* *$ & $5(3,2 \%)$ & 0,13 \\
DD & Ilha oceânica & $3(1,9 \%)$ & \\
\hline
\end{tabular}


O teste de correlação de Spearman detectou uma correlação moderada positiva de 0,5709 entre as variáveis envolvidas (a extensão do litoral de cada município e o número de encalhes), e ( $\mathrm{p}$ valor $=0,02623)$ foi menor que $o$ nível de significância ( $\alpha=0,05)$, confirmando, portanto, a correlação estatisticamente significativa entre essas variáveis (Figura 3).

Todos os peixes-bois-marinhos resgatados no período foram encontrados no litoral norte do estado, sendo 33,3\% (5/15) no município de Goiana; 6,7\% (1/15) em Igarassu; 6,7\% (1/15) em Ipojuca; $46,7 \%$ (7/15) em Olinda; e 6,7\% (1/15) em Recife.

Analisando a sazonalidade conforme intervalo de anos, verificou-se que a média de encalhes anualmente começa a crescer a partir dos anos 1992-1995, que apresentaram uma média de 3 encalhes, chegando ao auge nos anos 2004-2007 com uma média de 9,5 encalhes nesse período. A partir disso, observou-se uma tendência de queda no número médio de encalhes anual; entre 2008 e 2011 foi registrado em média 7,3 encalhes e entre o período de 2012 e 2015 somente 4 encalhes. Além disso, baseado no teste de Kruskal-Wallis, existe diferença estatisticamente significativa entre as médias de encalhes ao longo dos anos, onde $(p-$ valor $=0,01244)$ foi menor que o nível de significância $(\alpha=0,05)$ (Figura 4 ).

Figura 4 - Relação da média de encalhes por ano (1984-2015)

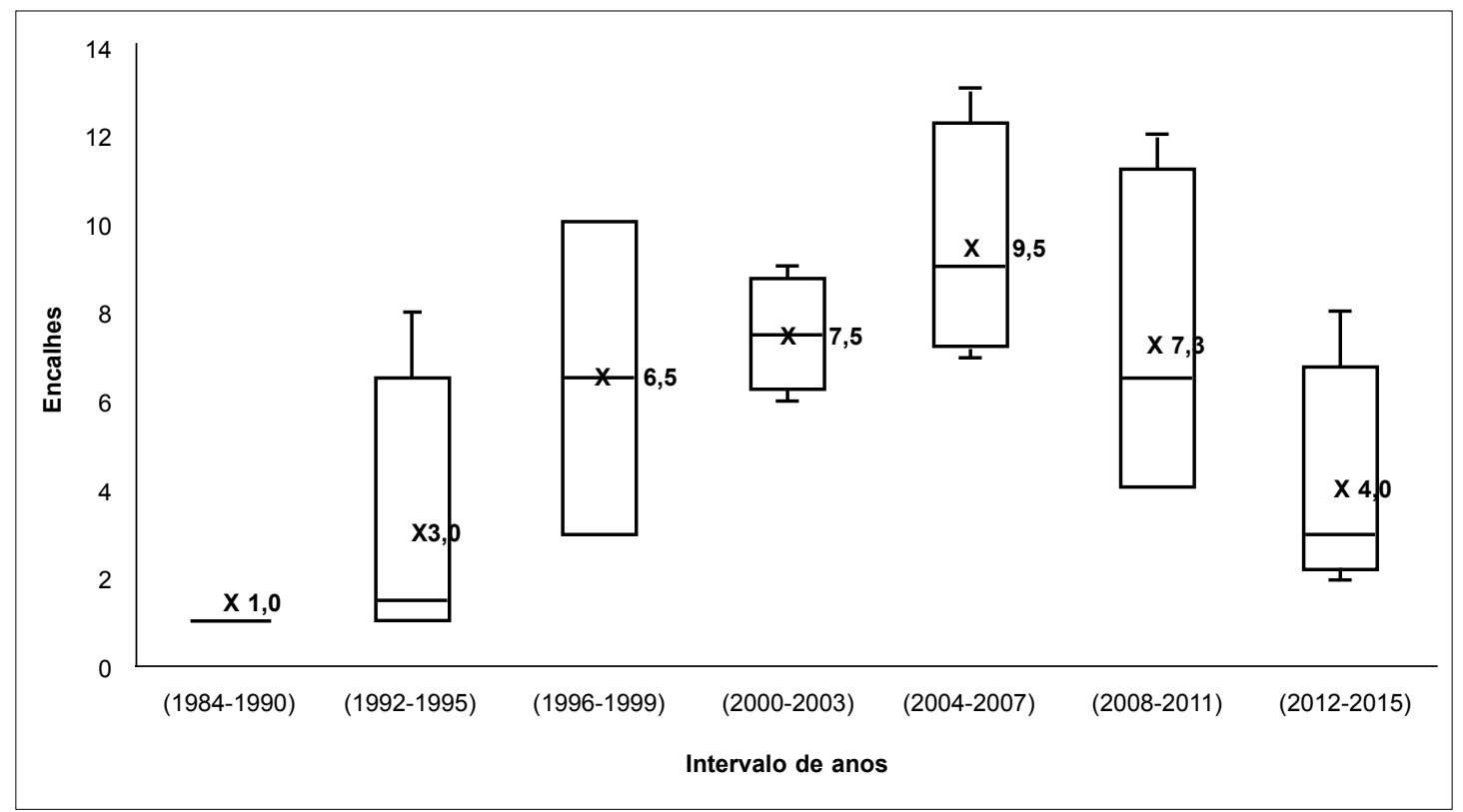


Quanto à relação entre o número de encalhes por ano e os fenômenos meteorológicos, verificou-se que existe diferença estatisticamente significativa entre a frequência de encalhes por influência de fenômenos climáticos, onde $(\mathrm{p}$ - valor $=1.78 \mathrm{e}-07)$ foi menor que o nível de significância $(\alpha=0,05)$ (Figura 5). Entretanto, ao analisar a relação entre a frequência de encalhes por influência de fenômenos (El Niño e La Niña), percebeu-se que não houve estatisticamente diferenças significativas entre a média e a variabilidade dos dados observados, $\operatorname{com}(\mathrm{p}-$ valor $=0,8149)$ maior que o nível de significância $(\alpha=0,05)$ (Figura 6).

Figura 5 - Ocorrência do fenômeno climático por número de encalhes, utilizando o teste de Qui-quadrado

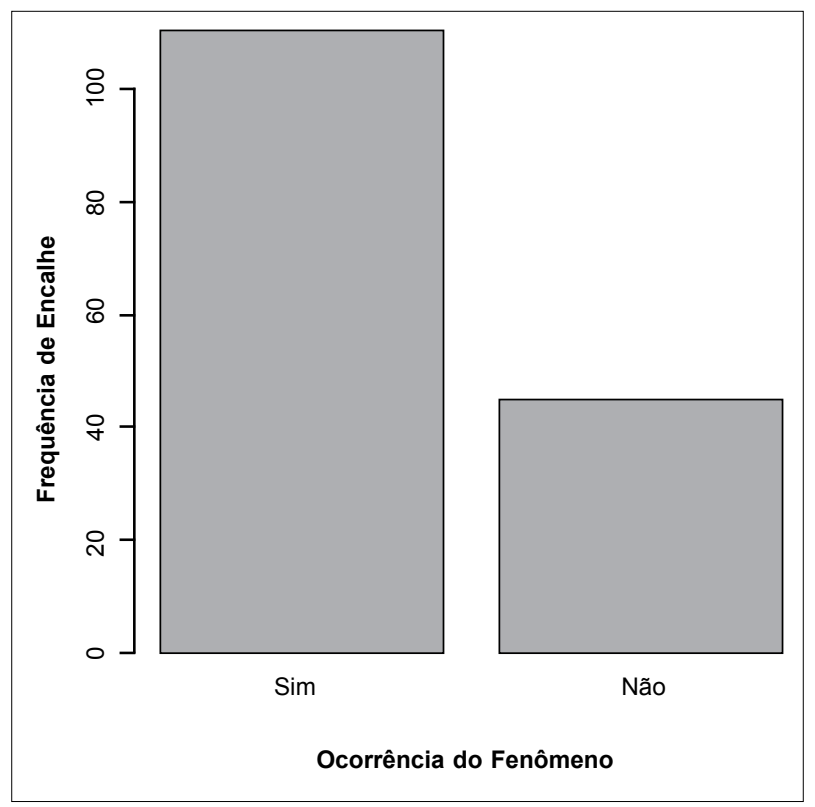

Figura 6 - Número de encalhes por tipo de fenômeno, utilizando o teste de Mann-Whitney

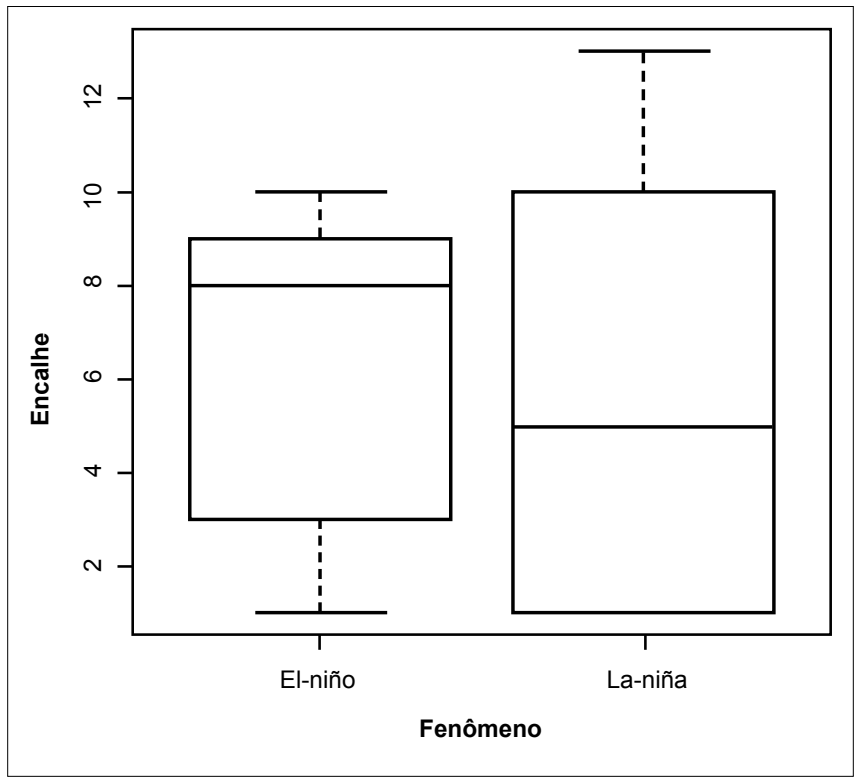


Analisando a sazonalidade com intervalos bimestrais, verificou-se que a maior média registrada de encalhes foi observada no período de setembro a outubro, com o valor médio de 18,5 encalhes nesse intervalo, seguido de perto pela média de encalhes entre os meses de novembro e dezembro (16). Já entre os meses de janeiro e fevereiro, foi contabilizada uma média de 15,5 encalhes, e o período com o menor número de encalhes médio foi entre os meses de maio e junho, com média equivalente de 6 encalhes, e julho e agosto com média de 8,5 encalhes (Figura 7).

Figura 7 - Sazonalidade dos registros de encalhes conforme os intervalos bimestrais entre 1984 e 2015

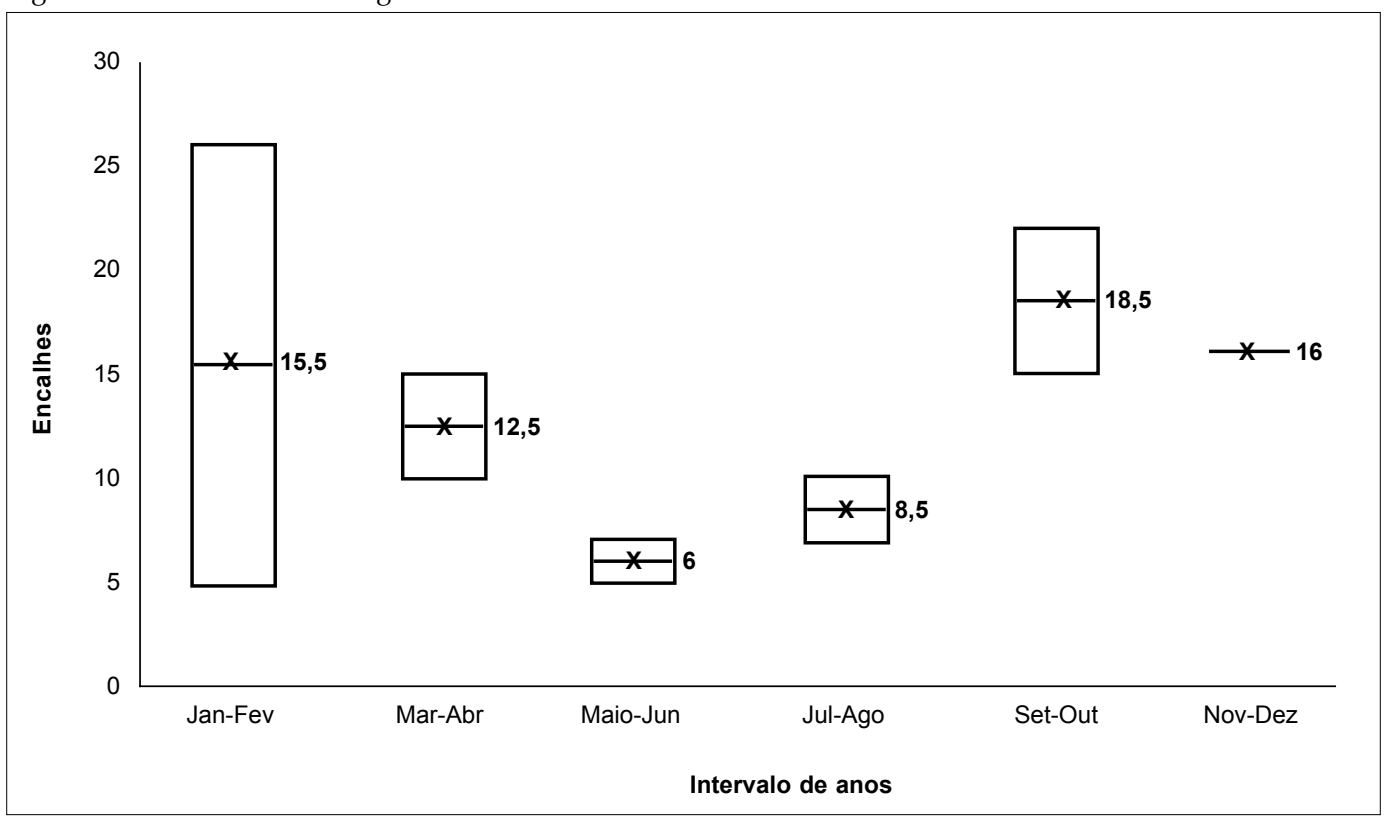

A partir do teste de Kruskal-Wallis, não houve diferença estatisticamente significativa entre as médias de encalhes conforme os intervalos bimestrais, onde ( $\mathrm{p}$ - valor $=$ $0,3329)$ foi maior que o nível de significância $(\alpha=0,05)$.

\section{DISCUSSÃO}

Com os dados obtidos por meio das ocorrências de encalhes registradas, sugere-se que o estado de Pernambuco possui uma importante diversidade de mamíferos aquáticos, incluindo espécies migratórias e ameaçadas de extinção. Os resultados obtidos foram semelhantes aos observados na Bacia de Sergipe-Alagoas, onde se constatou, a partir dos encalhes, a presença de 18 espécies (Borges et al., 2019), com um número ligeiramente maior ao reportado na costa centro-norte do estado do Rio de Janeiro, com o relato de 20 espécies (Parente et al., 2017). Em uma área mais ampla, considerando a costa norte do Brasil, Siciliano et al. (2008) registraram a ocorrência de 22 espécies de mamíferos aquáticos.

Em algumas áreas de Pernambuco, o peixe-boi-marinho havia sido considerado como extinto (Lima, 1997; Luna, 2001); todavia, a espécie foi registrada no estado por meio de levantamento populacional por sobrevoo (Alves et al. 2013) e por registro de encalhes (Balensiefer et al., 2017). O programa de soltura de peixes-bois no Brasil iniciou-se em 1994, em Alagoas, e em seguida na Paraíba (Normande et al. 2016). Neste levantamento, os regis- 
tros de encalhes da espécie ocorreram desde 1984. Portanto, pode-se afirmar que não se tratava de animais reintroduzidos. Destaca-se ainda que nenhum dos 15 registros de peixes-bois deste estudo foi de animal reintroduzido. Adicionalmente, os espécimes de peixes-bois reintroduzidos nos estados da Paraíba e Alagoas realizaram deslocamentos para o litoral de Pernambuco, sendo essa uma área intermediária entre os sítios de soltura da espécie no Brasil (Normande, 2014; Luna, 2013). Com isso, Pernambuco destaca-se como importante local para a conservação de um dos mamíferos aquáticos mais ameaçados de extinção do Brasil (Normande et al., 2016).

O peixe-boi adulto, capturado no município de Olinda, juntamente com uma fêmea reintroduzida, foi o primeiro e único peixe-boi nativo capturado, avaliado clinicamente e em seguida solto na natureza no estado de Pernambuco (Attademo et al., 2010). Destaca-se que esse local era antes considerado como de descontinuidade da espécie e que os dois animais permaneceram sendo observados juntos por cerca de um ano. Após isso, a fêmea, denominada Lua, teve a parição de um filhote (Attademo et al., 2018). O filhote e a fêmea não foram contabilizados neste estudo, uma vez que não ocorreu o encalhe dos mesmos.

A presença de S. guianensis no litoral de Pernambuco foi registrada anteriormente em estudos relacionados aos aspectos comportamentais (Araújo et al., 2007, 2008). No presente trabalho foi a espécie mais frequente nos encalhes, confirmando sua presença no estado. Esse maior quantitativo pode ser justificado pelo seu hábito costeiro, tornando-a mais vulnerável às interações com atividades antrópicas e, consequentemente, gerando condições mais propícias ao encalhe nas praias, quando comparadas às espécies oceânicas (Jefferson et al., 1993; Batista et al., 2012).

A ocorrência de T. truncatus também já havia sido registrada no litoral de Pernambuco (Meirelles et al., 2016), e o presente estudo corrobora o anterior, destacando o estado como importante área para a conservação da espécie e reforçando a importância da Remane para obtenção de dados sobre a mesma.

Apesar dos quantitativos de encalhes de S. guianensis e T. manatus serem menores que em outros estados (Balensiefer et al., 2017), possivelmente devido a um menor esforço de monitoramento, deve-se levar em consideração que os encalhes refletem apenas uma parcela da mortalidade e que esses mamíferos constam na Lista de Espécies Ameaçadas (ICMBio, 2018). Além disso, características do ciclo de vida desses animais, como natalidade e idade de primeira reprodução, aliadas às atividades antrópicas como a captura acidental, podem levar tais populações ao colapso (Geraci \& Lounsbury, 2005).

As duas espécies de lobos-marinhos encontradas no estudo, A. tropicalis e A. australis, não possuem distribuição no Nordeste do Brasil (Hofmeyr, 2015; Cárdenas-Alayza; Oliveira \& Crespo, 2016). Esses registros possivelmente corresponderam a animais erráticos, que se perderam dos grupos de origem por razões desconhecidas, podendo ser correntes marítimas, interações antrópicas ou causas correlatas.

As informações sobre a ocorrência de L. longicaudis ainda se apresentam de forma incipiente no estado de Pernambuco, com relatos nas últimas décadas (Rosa-Ribeiro; Ranulpho \& Venticinque, 2017). Os registros obtidos neste trabalho reforçam as constatações acerca da presença desse mustelídeo e refutam o entendimento de que a espécie havia sido extinta do estado, conforme sugerido por Pontes, Beltrão e Santos (2019). Dessa forma, sugere-se a revisão do status de conservação e a necessidade de pesquisa direcionada ao levantamento populacional dessa espécie no estado. 
As informações ecológicas sobre espécies de animais migratórios são importantes para a adoção de medidas públicas na gestão ambiental, em especial nas áreas marinhas (Koblitz et al., 2014; Borja \& Elliott, 2013). A Convenção sobre Espécies Migratórias (CMS) trata-se de um acordo intergovernamental, do qual o Brasil é signatário. Os animais contemplados nessa convenção podem estar listados em um dos apêndices da CMS ou em ambos. Além disso, incentiva que os países em toda a área de distribuição das espécies cumpram acordos globais ou regionais para a conservação e o manejo de espécies individuais ou grupos de espécies relacionadas (Jordace \& Arthou, 2017). O estado de Pernambuco possui seis espécies listadas na referida convenção, sendo duas no Apêndice I, duas no Apêndice II e duas em ambos, destacando a necessidade de adoção de medidas de conservação, assim como da preservação do habitat nos quais estão inseridas.

O Brasil, além de dispor de legislação específica para proteção da fauna marinha, é signatário de importantes acordos internacionais, a exemplo da Convenção de Biodiversidade e Convenção sobre Espécies Migratórias, ou Convenção de Bonn (MMA, 2018; Campello \& Barros, 2018). As espécies migratórias são aquelas que realizam movimentação entre um local de reprodução e outros locais, de forma sazonal (Dingle, 2014). Foram identificadas em Pernambuco oito espécies que realizam migração (CMS, 2018).

A biodiversidade marinha, incluindo os mamíferos, sofre uma série de impactos que podem vir a afetar a sua sobrevivência, como a poluição, a pesca acidental e a degradação do habitat (Craig, 2012). No estado de Pernambuco, alguns desses problemas têm sido evidenciados ao longo da zona costeira. Esses fatores, associados à presença de espécies ameaçadas e migratórias, demonstram a importância de ações de resgate da fauna marinha, assim como de melhoria do habitat e mitigação dos impactos existentes.

Os mamíferos aquáticos também são importantes sentinelas ambientais, os quais auxiliam, entre outros aspectos, na mensuração da poluição do ambiente (Moore, 2008).

A maioria dos animais encalhados correspondeu a carcaças em avançado estado de decomposição. Nas ocasiões em que foi possível identificar a causa da morte, em muitos foi detectada a interação antrópica, principalmente relacionada às atividades pesqueiras. A ausência desses indícios, em grande parte observada nos animais em avançado estado de decomposição, não exclui a possibilidade de ter havido alguma relação para os encalhes ou óbitos. Essa informação é de grande relevância, pois em $60 \%$ dos resgates não foi possível identificar a causa do óbito. Dessa forma, torna-se essencial a redução da taxa de causas de morte não identificadas para os animais em Pernambuco, o que só pode ser alcançado por meio de um monitoramento sistemático e ostensivo.

O modelo de monitoramento de praias permite o resgate imediato dos animais encalhados vivos, possibilitando a sua reabilitação e, no caso dos espécimes mortos em bom estado de conservação, a correta identificação da causa mortis.

O esforço de coleta variou no período. Até 1994 os atendimentos aos encalhes eram mais oportunísticos do que sistemáticos. A partir desse período, com o início do programa de reintrodução de peixes-bois, as atividades de campanhas educativas se intensificaram no estado de Pernambuco, permitindo formar uma abrangente rede de colaboradores que auxiliaram na cobertura de relatos dos encalhes. Para acompanhar os peixes-bois reintroduzidos, uma equipe de monitoramento diário percorreu as possíveis áreas de uso dos animais (Normande, 2014). Nessas atividades, eram fornecidas orientações aos colaboradores sobre o que fazer em caso de encalhes, assim como transmitido o contato das insti- 
tuições, por meio de cartazes e palestras de conscientização. Portanto, é provável que o aumento de encalhes, após 1994, tenha ocorrido como consequência do maior esforço.

Apesar dessa sistematização do atendimento, no período houve variações no esforço de coleta de informações sobre os encalhes, especialmente devido a mudanças na infraestrutura (veículos, pessoal, materiais e financeiro). Esses fatores podem ter interferido no número de registros de encalhes durante os anos, mas não na análise do registro de espécies com base nas informações de 31 anos de pesquisa.

Uma descontinuidade nos esforços presentes e futuros poderá resultar em uma subnotificação de mamíferos aquáticos, assim como uma lacuna de informações para a elaboração de estratégias conservacionistas para as espécies. Desse modo, recomenda-se a ampliação dos levantamentos populacionais, assim como do pronto atendimento aos encalhes no estado de Pernambuco através da implementação de programas de monitoramentos sistemáticos.

Considerando a distribuição espacial dos encalhes, o litoral sul, onde está inserida a Apacc, foi a região com o menor número. Não é possível afirmar que haja uma maior proteção às espécies por essa razão; entretanto, sugere-se que o seu uso possa estar ocorrendo de forma mais ordenada, reduzindo os impactos ao ambiente e, consequentemente, o número de animais encalhados.

O litoral de Pernambuco possui diversas atividades econômicas, como a pesca, o turismo, a navegação e a exploração imobiliária, entre outras, as quais podem acentuar os impactos a essas espécies. Nesse aspecto, foi observado um maior número de registros em áreas com maior urbanização, com a proximidade da base do ICMBio e com relação à extensão do litoral.

Os municípios de Recife, Olinda e Paulista formam a principal região metropolitana do estado, possuindo atividades antrópicas em toda a orla, incluindo recreação e turismo. Além disso, a Empresa de Manutenção e Limpeza Urbana de Pernambuco (Emlurb) foi uma importante colaboradora, notificando de forma imediata a presença de mamíferos aquáticos encalhados, sem destinar as carcaças antes da chegada da equipe responsável pela sua coleta. As análises apresentadas corroboraram com essa informação, pois os municípios supracitados foram aqueles com o maior número de atendimento aos encalhes.

Na Ilha de Itamaracá estava situada a sede do ICMBio/CMA e, devido à presença diária da equipe, além do forte reconhecimento da instituição por meio da visitação pública aos animais cativos, também foi possível a realização frequente de resgates. Os resgates no município de Igarassu ocorreram na Ilha da Coroa do Avião, a qual, apesar de pertencer a este município, localiza-se imediatamente ao sul da Ilha de Itamaracá. Esses dois fatores influenciaram na agilidade de chegada das equipes aos locais dos encalhes, aumentando a taxa de recuperação de carcaça nos dois municípios.

De acordo com a Agência Pernambucana de Águas e Clima (Apac), no que se refere ao clima em Pernambuco, a variação de temperatura entre as estações varia pouco, sendo conhecidas duas grandes estações: chuvosa e seca, com a pluviosidade caracterizada como maior variação climática. O período chuvoso coincide com a primavera e verão do restante do Brasil; enquanto o período seco, com o outono e inverno.

O estudo mostrou que a maioria dos atendimentos ocorreu no período chuvoso, entre setembro e março. Esse período coincide também com o período reprodutivo de algumas espécies, entre elas a baleia jubarte (Zerbini et al., 2004; Wedekin et al., 2010), e corrobora com o período de maior ocorrência de encalhes de peixe-boi-marinho em outras 
regiões do país (Balensiefer et al., 2017). Todavia, nessa época do ano ocorre uma maior ocupação das praias devido ao turismo, podendo ter resultado em um maior número de notificações de encalhes.

A presença dos fenômenos climáticos El Niño ou La Niña, de acordo com os dados obtidos, pode ocasionar um aumento do número de encalhes. Dessa forma, nos anos em que ocorrer algum desses eventos, o monitoramento deve ser intensificado, procurando aumentar a taxa de recuperação das carcaças.

Tendo sido observada a presença de peixes-bois com comportamento reprodutivo em Pernambuco, a frequência de encalhes de filhotes pode aumentar nos próximos anos, caso não sejam adotadas medidas preventivas de conscientização e educação ambiental, monitoramento sistemático de praias e mitigação dos impactos existentes, entre outras ações conservacionistas para a espécie.

\section{CONCLUSÃO}

Conforme verificado no presente estudo, o litoral de Pernambuco possui a presença de mamíferos aquáticos ameaçados de extinção e de outros pertencentes ao CMS, sendo necessária a implementação de ações conservacionistas para a proteção dos animais e de seus habitats.

Entre as estratégias prioritárias, destacam-se o atendimento sistemático aos encalhes na região, o resgate e monitoramento, as ações de mitigação aos impactos antropogênicos, as atividades de educação e conscientização ambiental, entre outras a serem incentivadas na região.

Também se destaca a importância da elaboração da lista de espécies ameaçadas de extinção no estado visando subsidiar os planos de ação a serem implantados. Estudos de impactos ambientais e a elaboração de mapas de sensibilidade poderão auxiliar no estabelecimento de políticas públicas que minimizem o estado de conservação das espécies ameaçadas.

A relação das espécies ameaçadas, ou cujo status está indefinido por falta de dados (DD), assim como as migratórias, fortalece a necessidade de uma ampla rede de cooperação entre órgãos governamentais de diferentes áreas, instituições de ensino e pesquisa e a sociedade em geral, considerando que a classificação das espécies quanto ao grau de ameaça e tipo de movimentos seguiu o padrão nacional.

Agradecimentos - Agradecemos ao Centro Nacional de Pesquisa e Conservação de Mamíferos Aquáticos (ICMBio/CMA), à Fundação Mamíferos Aquáticos (FMA), à Empresa de Manutenção e Limpeza Urbana de Pernambuco (Emlurb), ao Instituto Mamíferos Aquáticos (IMA), ao Projeto Cetáceos da Costa Branca-UERN (PCCB-UERN), à Universidade Federal Rural de Pernambuco (UFRPE), aos colaboradores que auxiliaram no registro dos encalhes e às demais instituições parceiras que auxiliaram na coleta de carcaça e no atendimento aos animais durante esta pesquisa.

\section{REFERÊNCIAS BIBLIOGRÁFICAS}

Alves, M.D.O.; Schwamborn R.; Borges J.C.G.; Marmontel, M.; Costa, A.F.; Schettini, C.A.F. \& Araújo, M.E. Aerial survey of manatees, dolphins and sea turtles off northeastern Brazil: 
correlations with coastal features and human activities. Biol. Conserv., Essex, v. 161, n. 1, p. 91-100, 2013.

Araújo, J.P.; Araújo, M.E.; Souto, A.; Parente, C.L. \& Geise, L. The influence of seasonality, tide and time of activities on the behavior of Sotalia guianensis (Van Bénéden) (Cetacea, Delphinidae) in Pernambuco, Brazil. Rev. Bras. Zool., São Paulo, v. 24, n. 4, p. 1122-1130, 2007.

Araújo, J.P.; Souto, A.; Geise, L. \& Araújo, M.E. The behavior of Sotalia guianensis (Van Bénéden) in Pernambuco waters, Brazil, and a further analysis of its reaction to boat traffic. Rev. Bras. Zool., São Paulo. v. 25, n. 1, p. 1-9, 2008.

Attademo, F.L.N.; Alencar, A.E.B.; Foppel, E.; Luna, F.O.; Magalhaes, L.H.R. Registro da primeira captura de peixe-boi-marinho (Trichechus manatus) adulto no Brasil, p. 218-218, in Anais do XIV Reunião de Trabalhos de Especialistas em Mamíferos Aquáticos da América do Sul e $8^{\circ}$ Congresso da Sociedade Latinoamericana de Especialistas em Mamíferos Aquáticos, Florianópolis, 403 p., 2010.

Attademo, F.L.N.; Balensiefer, D.C.; Freire, A.C.B.; Sousa, G.P.; Cunha, F.A.G.C. \& Luna, F.O. Debris ingestion by the Antillean manatee (Trichechus manatus manatus). Mar. Pollut. Bull., Oxford, v. 101, n. 1, p. 284-287, 2015.

Attademo, F.L.N.; Normande, I.C.; Souza, G.P.; Freire, A.C.B.; Borges, J.C.G.; Foppel, E.F.C.; Lima, R.P.; Sommer, I.B. \& Luna, F.O. Histórico de reintrodução de peixe-boimarinho (Trichechus manatus manatus) no Brasil, p. 194-194, in Anais do XVIII Reunión de Trabajo de Expertos en Mamíferos Acuáticos y al XII Congreso de la SOLAMAC e XVIII Reunión de Trabajo de Expertos en Mamíferos Acuáticos y al XII Congreso de la SOLAMAC, Lima, 368 p., 2018.

Balensiefer, D.C.; Attademo, F.L.N.; Souza, G.P.; Freire, A.C.B.; Cunha, F.A.G.C.; Alencar, A.E.B.; Silva, F.J.L. \& Luna, F.O. Three decades of Antillean manatee (Trichechus manatus manatus) strandings along the Brazilian coast. Trop. Conserv. Sci., v. 10, n. 1, p. 1-9, 2017.

Batista, R.L.G.; Schiavetti, A.; Santos, U.A. \& Reis, M.S.S. Cetaceans registered on the coast of Ilhéus (Bahia), northeastern Brazil. Biota Neotrop., Campinas, v. 12, n. 1, 2012.

Berrow, S. Biological diversity of cetaceans (whales, dolphins and porpoises) in Irish waters, p. 115-120, in Nunn, J.D. (ed.). Marine biodiversity in Ireland and adjacent waters, Proceedings of a conference, Ulster Museum, Belfast, 188 p., 2001.

Borges, J.C.G.; Vergara-Parente, J.E.; Alvite, C.M.C.; Marcondes, M.C.C. \& Lima, R.P. Embarcações motorizadas: uma ameaça aos peixes-bois-marinhos (Trichechus manatus) no Brasil. Biota Neotrop., Campinas, v. 7, n. 3, p. 199-204, 2007.

Borges, J.C.G.; Moreira, A.L.; Batista, R.L.G.; MELO, B.J.A.; REIS, E.C. \& Vergara-Parente, J.E. Mamíferos marinhos da Bacia Sergipe-Alagoas, p. 116-149, in Reis, E.C. \& Carneiro, M.E.R. (eds.). Quelônios, aves e mamíferos marinhos da Bacia de Sergipe-Alagoas, São Cristóvão: Editora UFS, 152 p., 2019.

Borja, Á. \& Elliott, M. Marine monitoring during an economic crisis: the cure is worse than the disease. Mar. Pollut. Pull., Oxford, v. 68, n. 1, p. 1-3, 2013.

Brasil. Decreto Federal de 23 de outubro de 1997. Dispõe sobre a criação da Área de Proteção Ambiental da Costa dos Corais, nos Estados de Alagoas e Pernambuco, e dá outras 
providências. Presidência da República, Brasília, 1997. Disponível em: http://www.planalto.gov. br/ccivil_03/dnn/Anterior\%20a\%202000/1997/Dnn5976.htm. Acesso em: 15 abr. 2020.

Campello, L.G.B. \& Barros, A.C.V. A era da afirmação dos direitos dos animais no cenário global e seu fundamento na solidariedade entre espécies. Rev. Bras. Direito Anim., Salvador, v. 13, n. 2, p. 95-109, 2018.

Cárdenas-Alayza, S.; Oliveira, L. \& Crespo, E. South American Fur Seal (Arctocephalus australis). The IUCN Red List of Threatened Species, Cambridge, 2016. Disponível em: https://dx.doi.org/10.2305/IUCN.UK.2016-1.RLTS.T2055A45223529.en. Acesso em: 15 abr. 2020.

CMS. Apéndices I y II de la Convención sobre la conservación de las especies migratorias de animals silvestres (CMS). Convención sobre la conservación de las especies migratorias de animals silvestres, Bonn, 2018. Disponível em: https://www.cms.int/sites/default/files/basic page_documents/cms_cop12_ap\%C3\%A9ndices_s.pdf. Acesso em: 15 abr. 2020.

Cites. Convention on International Trade in Endangered Species of Wild Fauna and Flora, Genève, 2017. Disponível em: https://www.cites.org/eng/disc/text.php. Acesso em: 12 dez. 2018.

Costa, A.F.; Siciliano, S.; Emin-Lima, R.; Martins, B.M.L.; Sousa, M.E.M.; Giarrizzo, T. \& Silva-Júnior, J.S. Stranding survey as a framework to investigate rare cetacean records of the north and north-eastern Brazilian coasts. Zookeys, Sofia, v. 688, n. 1, p. 111-134, 2017.

Craig R.K. Marine biodiversity, climate change, and governance of the oceans. Diversity, v. 4, n. 2, p. 224-238, 2012.

Cubas, Z.S.; Silva, J.C.R. \& Catão-Dias, J.L. Tratado de animais selvagens: medicina veterinária, v. 1, São Paulo: Roca, 1237 p., 2014.

Dans, S.L.; Alonso, M.K.; Pedrasa, S.N. \& Crespo, E.A. Incidental catch of dolphins in trawling fisheries off Patagonia, Argentina: can populations persist? Ecolog. Applicat., Washington, v. 13, n. 3, p. 754-762, 2003.

Dingle, H. Migration: the biology of life on move. Croydon: Oxford University Press, 480 p., 2014.

Fire, S.E.; Flewelling, L.J.; Stolen, M.; Durden, W.N.; Wit M.; Spellman, A.C. \& Wang Z. Brevetoxin-associated mass mortality event of bottlenose dolphins and manatees along the east coast of Florida, USA. Mar Ecol. Prog. Ser., Califórnia, v. 526, n. 1, p. 241-251, 2015.

Geraci, J.G. \& Lounsbury, V.J. Marine mammal ashore. A field guide for strandings, Texas: A \& M University Sea Grant College Program, 371 p., Galveston, 2005.

Geraci, J.R. \& St. Aubin, D.J. Biology of marine mammals: insights through strandings. Washington: The Commissiom, 343 p., Springfield, 1979.

Hofmeyr, G.J.G. Subantarctic Fur Seal (Arctocephalus tropicalis). The IUCN Red List of Threatened Species, Cambridge, 2015. Disponível em: https://dx.doi.org/10.2305/IUCN. UK.2015-4.RLTS.T2062A45224547.en. Acesso em: 15 abr. 2020.

Ibama. Protocolo de conduta para encalhes de mamíferos aquáticos/Rede de encalhe de mamíferos aquáticos do Nordeste. Brasília: Ibama, 298 p., 2005.

ICMBio. Livro vermelho da fauna brasileira ameaçada de extinção. Brasília: ICMBio, 4162 p., 2018.

Inpe. El Niño e La Niña 2018. Disponível em: http://enos.cptec.inpe.br/\#. Acesso em: 11 nov. 2019. 
Jefferson, T.A.; Leatherwood, S. \& Webber, M.A. FAO Species identification guide. Marine mammals of the World. Roma: FAO/UNEP, 587 p., 1993.

Jordace, T. \& Arthou, L. Tratados e convenções internacionais recepcionados pelo Brasil para a preservação do meio ambiente. Rev. Interd. Direit, Valença, v. 14, n. 1, p. 215-234, 2017.

Koblitz, J.C.; Amundin, M.; Carlström, J.; Thomas, L.; Carlén, I.; Teilmann, J.; Tregenza, N.; Wennerberg, D.; Kyhn, L.; Svegaard, S.; Koza, R.; Kosecka, M.; Pawliczka, I.; TiberiLjungqvist, C.; Brundiers, K.; Wright, A.; Mikkelsen, L.; Tougaard, J.; Loisa, O.; Galatius, A.; Jüssi, I. \& Benke, H. Large-scale static acoustic survey of a low-density population estimating the abundance of the Baltic Sea harbor porpoise. J. Acoust. Soc. Am., Nova York, v. 136, n. 4, p. 2248-2248, 2014.

Lima, R.P. Peixe-boi-marinho (Trichechus manatus): distribuição, status de conservação e aspectos tradicionais ao longo do litoral Nordeste do Brasil. Dissertação de mestrado, Programa de Pós-Graduação em Oceanografia, Universidade Federal de Pernambuco, 86 p., Recife, 1997.

Lodi, L. \& Borobia, M. Baleias, botos e golfinhos do Brasil: guia de identificação. Rio de Janeiro: Technical Books, 479 p., 2013.

Luna, F.O. Distribuição, status de conservação e aspectos tradicionais do peixe-boi- marinho (Trichechus manatus manatus) no litoral norte do Brasil. Dissertação de mestrado, Programa de Pós-Graduação em Oceanografia, Universidade Federal de Pernambuco, 122 p., Recife, 2001.

Luna, F.O. Population genetics and conservation strategies for the West Indian manatee (Trichechus manatus Linnaeus, 1758) in Brazil. Tese de doutorado, Programa de Pós-Graduação em Oceanografia, Universidade Federal de Pernambuco, Recife, 236 p., 2013.

Mader, A.; Sander, M. \& Balbão, T.C. Atividade antrópica associada à mortalidade de mamíferos marinhos no litoral norte do Rio Grande do Sul, Brasil. Biodivers. Pampeana, Porto Alegre, v. 4, n. 1, p. 424-28, 2006.

MMA. Espécies Migratórias. Convenção sobre Espécies Migratórias de Animais Selvagens (CMS ou Convenção de Bonn). Ministério do Meio Ambiente, 2018. Disponível em: http:// www.mma.gov.br/informma/item/887-esp\%C3\%A9cies-migrat\%C3\%B3rias.html. Acesso em: 16 dez. 2018.

Meirelles, A.C.O.; Campos, T.M.; Marcondes, M.C.C.; Groch, K.R.; Souto, L.R.A.; Reis, M.S.S.; Normande, I.C.; Luna, F.O.; Nascimento, L.F.; Silva, F.J.L.; Vergara-Parente, J.E.; Borges, J.C.G.; Jesus, A.H.; Attademo, F.L.N. \& Júnior, J.M.S. Reports of strandings and sightings of bottlenose dolphins (Tursiops truncatus) in northeastern Brazil and Brazilian oceanic islands. Lat. Am. J. Aquat. Mamm., v. 11, n. 1-2, p. 178-190, 2016.

Moore, S.E. Marine mammals as ecosystem sentinels. J. Mammal., Oxford, v. 89, n. 3, p. 534540, 2008.

Normande, I.C.; Attademo, F.L.N. \& Luna, F.O. Antillean manatee release program in Brazil, p. 162-165, in Soorae, P.S. (ed.). Global Re-introduction Perspectives: 2016. Case-studies from around the globe. IUCN/SSC Reintroduction Specialist Group and Abu Dhabi, xiv + 276 p., Gland, 2016. 
Normande, I.C. Manejo para conservação de peixes-bois-marinhos (Trichechus manatus, Linnaeus, 1758) no Brasil: programas de soltura e monitoramento. Dissertação de mestrado, Programa de Pós-Graduação em Diversidade Biológica e Conservação nos Trópicos, Instituto de Ciências Biológicas e da Saúde, Universidade Federal de Alagoas, 115 p., Maceió, 2014.

Parente, C.L.; Vergara-Parente, J.E. \& Lima, R.P. Strandings of Antillean manatees, Trichechus manatus manatus, in Northeastern Brazil. Lat. Am. J. Aquat. Mamm., v. 3, n. 1, p. 69-75, 2004.

Parente, C.L.; Lima, R.P. \& Vergara-Parente, J.E. Ocorrência e comportamento de um botocinza, Sotalia guianensis, solitário no Nordeste do Brasil: quando considerar um encalhe? Arq. Ciên. Mar, Fortaleza, v. 39, n. 1-2, p. 74-80, 2006.

Parente, C.L.; Moura, J.F.; Secco, H.K.C. \& Di Beneditto, A.P.M. Diversidade e distribuição de cetáceos na área de influência das atividades de E\&P na Bacia de Campos, p. 35-61, in Reis, E.C. \& Curbelo-Fernandez, M.P. (eds.). Mamíferos, quelônios e aves: caracterização ambiental regional da Bacia de Campos, Atlântico Sudoeste. Rio de Janeiro: Elsevier. Habitats, 152 p., 2017.

Pontes, A.R.M.; Beltrão, A.C.M. \& Santos, A.M.M. Reconsidering mammal extinctions in the Pernambuco Endemism Center of the Brazilian Atlantic Forest: a critique. Anim. Biodiv. Conserv., Barcelona, v. 42, n. 1, p. 69-77, 2019.

Reeves, R.R.; Stewart, B.S.; Clapham, P.J. \& Powell, J.A. National Audubon Society Guide to Marine Mammals of the World. Knopf, Random House, 528 p., New York, 2002.

Rosas-Ribeiro, P.F.; Ranulpho, R. \& Venticinque, E.M. New records and update on the geographic distribution of Lontra longicaudis (Olfers, 1818) (Carnivora: Mustelidae) in Seasonally Dry Tropical Forests of northeastern Brazil. Check List, J. Spec. List Dist., v. 13, n. 3, p. 1-8, 2017.

Ruoppolo, V.; Vanstreels, R.E.T.; Marigo, J. \& Catão-Dias, J.L. Unusual incidence of chronic pneumonia associated with cholesterol deposits in stranded and bycaught franciscanas Pontoporia blainvillei. Dis. Aquat. Organ., v. 92, n. 1, p. 75-81, 2010.

Siciliano, S.; Emin-Lima, N.R.; Costa, A.F.; Rodrigues, A.F.; Magalhães, F.A.; Tosi, C.H.; Garri, R.G.; Silva, C.R. \& Júnior, J.S.S. Revisão do conhecimento sobre os mamíferos aquáticos da costa norte do Brasil. Arq. Mus. Nac., Rio de Janeiro, v. 66, n. 2, p. 381-401, 2008.

Wedekin, L.L.; Neves, M.C.; Marcondes, M.C.C.; Baracho, C.; Rossi-Santos, M.R.; Engel, M.H. \& Simões-Lopes, P.C. Site fidelity and movements of humpback whales (Megaptera novaeangliae) on the Brazilian breeding ground, southwestern Atlantic. Mar. Mammal. Sci., Califórnia, v. 6, n. 4, p 787-802, 2010.

Zerbini, A.N.; Andriolo, A.; Rocha, J.M.; Simões-Lopes, P.C.; Siciliano, S.; Pizzorno, J.P.; Waite, J.M.; De Master, D.P. \& Van Blaricom, G.R. Winter distribution and abundance of humpback whales (Megaptera novaeangliae) off Northeastern Brazil. J. Cetacean Res. Manage., Cambridge, v. 6, n. 1, p. 101-107, 2004. 